\title{
Boosting Self-Trapped Emissions in Zero-Dimensional Perovskite Heterostructures
}

\author{
Jun Yin, Jean-Luc Brédas,* Osman M. Bakr,* and Omar F. Mohammed* \\ Cite This: Chem. Mater. 2020, 32, 5036-5043 \\ Read Online
}

ABSTRACT: Zero-dimensional (OD) inorganic perovskites have attracted great interest for white-light-emitting applications because of their broad band emissions originating from selftrapped excitons. In this work, we explore and decipher exciton self-trapping in a series of $0 \mathrm{D}$ inorganic perovskites, $\mathrm{A}_{4} \mathrm{PbX}_{6}$ and $\mathrm{A}_{4} \mathrm{SnX}_{6}(\mathrm{~A}=\mathrm{K}, \mathrm{Rb}$, and $\mathrm{Cs} ; \mathrm{X}=\mathrm{Cl}, \mathrm{Br}$, and $\mathrm{I})$ at the density functional theory level within the theoretical framework of the onedimensional configuration coordinate diagram. We demonstrate that the formation of self-trapped states in $\mathrm{A}_{4} \mathrm{PbX}_{6}$ and $\mathrm{A}_{4} \mathrm{SnX} 6$ can be attributed to local structural distortions of individual $\left[\mathrm{PbX}_{6}\right]^{4-}$ and $\left[\mathrm{SnX}_{6}\right]^{4-}$ octahedra. Importantly, with the goal of both potentially improving the stability of the $S n$ derivatives and enhancing the emission efficiency, we further propose and design

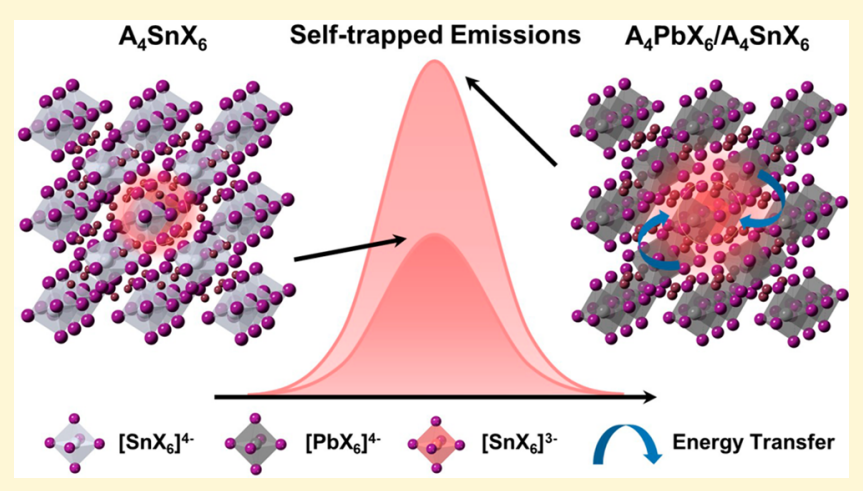
two types of $0 \mathrm{D}$ perovskite heterostructures, bulk $\mathrm{A}_{4} \mathrm{PbX}_{6} / \mathrm{A}_{4} \mathrm{SnX}$ mixtures and $\mathrm{A}_{4} \mathrm{PbX}_{6} / \mathrm{A}_{4} \mathrm{SnX} 6$ heterojunctions. We find that these $0 \mathrm{D}$ heterostructures exhibit type-I energy level alignment in which energy transfer from $\mathrm{A}_{4} \mathrm{PbX}_{6}$ to $\mathrm{A}_{4} \mathrm{SnX} \mathrm{X}_{6}$ is strongly promoted. Interestingly, these heterostructures show an increase in the transition dipole moments between the ground and self-trapped states compared to the pristine $0 \mathrm{D}$ perovskites. Our findings provide a new material design strategy for boosting self-trapped emissions with improved air stability for white-light-emitting applications.

\section{INTRODUCTION}

Zero-dimensional (OD) metal-halide perovskites have attracted broad interest in the field of optoelectronic devices, including light-emitting diodes, ${ }^{1,2}$ lasers, ${ }^{3}$ photodetectors, ${ }^{4,5}$ thermometry and thermography devices, 6 and solar concentrators, ${ }^{7}$ because of their remarkable optical properties, especially broad band emissions with high quantum yield. ${ }^{8-11}$ In terms of the crystal structure, once the dimensionality is reduced from three-dimensional $(3 \mathrm{D})$ to $0 \mathrm{D}$, the corner-sharing metal-halide octahedra in the 3D framework become isolated metal-halide octahedra. Such molecular-like OD crystal structures give rise to several peculiar photophysical properties that clearly differentiate them from 3D perovskites, such as lead-ionrelated emissions, ${ }^{12,13}$ broad band absorption arising from small localized polarons, ${ }^{14-16}$ high exciton binding energy, and narrow visible emission (whose origin, however, is still under debate). ${ }^{17-22}$ Moreover, upon photoexcitation, self-trapped excitons (STEs; i.e., excitons that cause lattice distortions) are easily generated in $\mathrm{OD}$ perovskites because of the strong interaction between excitons and lattice vibrations/distortions, as a consequence of large electron-phonon couplings. ${ }^{23-25}$

The emissions from STEs in OD perovskites are quite broad and can be tuned from the UV to the entire visible spectral range by changing the organic cations, metal ions, and/or halides. For example, $\mathrm{Pb}$-based $\mathrm{OD}$ perovskite crystals (typically $\mathrm{Cs}_{4} \mathrm{PbX}_{6}, \mathrm{X}=\mathrm{Cl}, \mathrm{Br}$, and $\mathrm{I}$ ) have large band gaps and broad band emissions in the UV spectral region. ${ }^{26-28}$ On the other hand, inorganic $\mathrm{Sn}$-based $0 \mathrm{D} \mathrm{A}_{4} \mathrm{SnX}_{6}$ single crystals $(\mathrm{A}=\mathrm{K}, \mathrm{Rb}$, and $\mathrm{Cs} ; \mathrm{X}=\mathrm{Cl}, \mathrm{Br}$, and $\mathrm{I})$ show highly tunable self-trapped exciton emissions between 500 and $620 \mathrm{~nm}$ with a photoluminescence quantum yield (PLQY) of $15 \pm 5 \% .{ }^{8,9} \mathrm{Sn}$ based organic-inorganic hybrid perovskites were demonstrated to exhibit very high PLQYs, as high as $95 \pm 5 \%$ for $\left(\mathrm{C}_{4} \mathrm{~N}_{2} \mathrm{H}_{14} \mathrm{Br}\right)_{4} \mathrm{SnBr}_{6}$ and $75 \pm 4 \%$ for $\left(\mathrm{C}_{4} \mathrm{~N}_{2} \mathrm{H}_{14} \mathrm{I}\right)_{4} \mathrm{SnI}_{6} \cdot{ }^{10,11}$ In this context, these $\mathrm{Sn}$-based $\mathrm{OD}$ perovskites appear to be very promising candidates for achieving UV-visible emissions for display applications. However, the pristine Sn-based OD inorganic perovskites suffer from environmental instability issues related to oxidation of $\mathrm{Sn}$ (II) to $\mathrm{Sn}$ (IV) as well as phase changes from $0 \mathrm{D}$ to $3 \mathrm{D}$ structures at room temperature. ${ }^{29}$

To address these issues, we propose two types of $0 \mathrm{D}$ perovskite heterostructures, bulk $\mathrm{A}_{4} \mathrm{SnX}_{6} / \mathrm{A}_{4} \mathrm{PbX}_{6}$ mixtures and $\mathrm{A}_{4} \mathrm{SnX}_{6} / \mathrm{A}_{4} \mathrm{PbX}_{6}$ heterojunctions. Since $\mathrm{A}_{4} \mathrm{PbX}_{6}$ compounds exhibit high air and photostability, they can not only serve as

Received: February 15, 2020

Revised: May 22, 2020

Published: May 22, 2020 
host matrix to protect $\mathrm{A}_{4} \mathrm{SnX} \mathrm{X}_{6}$ from oxidation and degradation but also act as an additional source of energy to enhance the broadband emissions of $\mathrm{A}_{4} \mathrm{SnX}_{6}$ owing to energy transfer from $\mathrm{A}_{4} \mathrm{PbX}_{6}$ to $\mathrm{A}_{4} \mathrm{SnX}_{6}$. In this work, we first rationalize the presence of self-trapped exciton emissions in a series of pristine $\mathrm{A}_{4} \mathrm{SnX}_{6}$ and $\mathrm{A}_{4} \mathrm{PbX}_{6}$ compounds using the one-dimensional configuration coordinate diagram approach. ${ }^{30,31}$ Such selftrapped states that cover most of the visible and UV spectral regions, as observed experimentally, ${ }^{8}$ could originate from local octahedron distortions. In the proposed bulk $\mathrm{A}_{4} \mathrm{SnX}_{6} / \mathrm{A}_{4} \mathrm{PbX}_{6}$ mixtures, the presence of a type-I energy level alignment and the strong spectral overlap ensures energy transfer from the $\mathrm{A}_{4} \mathrm{PbX}_{6}$ host to the $\mathrm{A}_{4} \mathrm{SnX}_{6}$ octahedra. In addition, there occurs an increase in the transition dipole moments, which contributes to enhanced broad band emissions in the bulk $\mathrm{A}_{4} \mathrm{SnX}_{6} / \mathrm{A}_{4} \mathrm{PbX}_{6}$ mixtures. The proposed $\mathrm{A}_{4} \mathrm{SnX}_{6} / \mathrm{A}_{4} \mathrm{PbX}_{6}$ heterojunctions with an $\mathrm{A}_{4} \mathrm{PbX}_{6}$ shell and an $\mathrm{A}_{4} \mathrm{SnX}_{6}$ core also exhibit a type-I energy level alignment that promotes efficient energy transfer and charge recombination.

\section{COMPUTATIONAL METHODS}

Density Functional Theory (DFT) Calculations. We performed DFT calculations of the $0 \mathrm{D}$ perovskite $\mathrm{A}_{4} \mathrm{PbX}_{6}$ and $\mathrm{A}_{4} \mathrm{SnX}_{6}(\mathrm{~A}=\mathrm{K}$, $\mathrm{Rb}$, and $\mathrm{Cs} ; \mathrm{X}=\mathrm{Cl}, \mathrm{Br}$, and I) crystals and their heterostructures using the generalized gradient approximation (GGA) with the PerdewBurke-Ernzerhof (PBE) functional in the Vienna $\mathrm{Ab}$ Initio Simulation Package (VASP). ${ }^{32,33}$ Starting from the experimental lattice parameters of trigonal-phase $\mathrm{A}_{4} \mathrm{PbX}_{6}$ and $\mathrm{A}_{4} \mathrm{SnX}_{6}$ (space group: $R \overline{3} c$ ), both the cell parameters and atomic positions of these crystal structures were further relaxed until the total Hellmann-Feynman forces on each atom were less than $0.01 \mathrm{eV} / \AA$ (the lattice parameters of the primitive cells are listed in Table S1, Supporting Information). Uniform Brillouin zone grids of a $6 \times 6 \times 6 k$-mesh for $\mathrm{A}_{4} \mathrm{PbX}_{6}$ and $\mathrm{A}_{4} \mathrm{SnX}_{6}$ bulk, a $2 \times 2 \times 2 \mathrm{k}$-mesh for $\mathrm{A}_{4} \mathrm{PbX}_{6}$ and $\mathrm{A}_{4} \mathrm{SnX}_{6}$ supercells and $\mathrm{A}_{4} \mathrm{PbX}_{6} / \mathrm{A}_{4} \mathrm{SnX} 6$ mixtures, and a $2 \times 2 \times 1 k$-mesh for $\mathrm{A}_{4} \mathrm{PbX}_{6} /$ $\mathrm{A}_{4} \mathrm{SnX}_{6}$ heterojunctions were used. The plane-wave basis set cutoff for the wave functions was set at $500 \mathrm{eV}$. The optical dielectric functions of $\mathrm{A}_{4} \mathrm{PbX}_{6}$ and $\mathrm{A}_{4} \mathrm{SnX} \mathrm{X}_{6}$ (Figures S5 and S6), including the real part $\left(\varepsilon_{1}\right)$ and the imaginary part $\left(\varepsilon_{2}\right)$, were calculated using the random phase approximation (RPA) method as implemented in VASP. The absorption coefficients were then calculated following the equation below based on $\varepsilon_{1}$ and $\varepsilon_{2}$ :

$$
\alpha=2 \omega\left[\frac{\left(\varepsilon_{1}^{2}(\omega)+\varepsilon_{2}^{2}(\omega)\right)^{1 / 2}-\varepsilon_{1}(\omega)}{2}\right]^{1 / 2}
$$

The ionization potentials (IPs) of $\mathrm{A}_{4} \mathrm{PbX}_{6}$ and $\mathrm{A}_{4} \mathrm{SnX} \mathrm{X}_{6}$ were calculated using the following equation: IP $=\Delta V-E_{\mathrm{VB}}$, where $E_{\mathrm{VB}}$ is the corrected valence band energy of bulk $\mathrm{A}_{4} \mathrm{PbX}_{6}$ and $\mathrm{A}_{4} \mathrm{SnX}_{6}$, and $\Delta V$ is the average electrostatic potential obtained at the slab center with respect to the vacuum layer (the top and bottom vacuum layers are $\sim 27 \AA$ ) for the $\mathrm{A}_{4} \mathrm{PbX}_{6}$ and $\mathrm{A}_{4} \mathrm{SnX}_{6}$ slabs (see Figure S14).

Phonon Mode Calculations. We calculated the Raman vibrational mode positions and intensities of $\mathrm{Cs}_{4} \mathrm{PbBr}_{6}$ and $\mathrm{Cs}_{4} \mathrm{SnBr}_{6}$ by using the Phonon code in the Quantum Espresso (QE) package. ${ }^{34,35}$ The local density approximation (LDA) exchange-correlation functional with norm-conserving pseudopotentials was used. The planewave basis set cutoffs were $80 \mathrm{Ry}$ for the wave functions and $500 \mathrm{Ry}$ for the charge. Uniform grids of $8 \times 8 \times 8$ for $\mathrm{Cs}_{4} \mathrm{PbBr}_{6}$ and $\mathrm{Cs}_{4} \mathrm{SnBr}_{6}$ were used for the $k$-point sampling together with the self-consistency threshold of $10^{-14}$ Ry to ensure no imaginary frequency modes in our calculations.

Dexter and Förster Energy-Transfer Rates. The Dexter energy-transfer rates between neighboring $\left[\mathrm{PbX}_{6}\right]^{4-}$ and $\left[\mathrm{SnX}_{6}\right]^{4-}$ octahedra were calculated using the following equation: $k_{\text {Dexter }}=\frac{2 \pi}{\hbar} V_{\text {LUMO }}{ }^{2} J \exp \left(\frac{-2 R_{\mathrm{DA}}}{L}\right),{ }^{36}$ where $V_{\mathrm{LUMO}}$ is the electronic couplings between the lowest unoccupied molecular orbitals (LUMOs), $J$ is the normalized spectral overlap integral, $R_{\mathrm{DA}}$ is the shortest distance between the donor $\left[\mathrm{PbX}_{6}\right]^{4-}$ and acceptor $\left[\mathrm{SnX}_{6}\right]^{4-}$, and $L$ is the average Bohr radius. The electronic couplings for the LUMO levels between neighboring $\left[\mathrm{PbX}_{6}\right]^{4-}$ and $\left[\mathrm{SnX}_{6}\right]^{4-}$ octahedra were calculated by using the Multiwfn code ${ }^{37}$ based on the electronic wave functions and eigenenergies obtained with the CAM-B3LYP functional and the LANL2DZ basis set for $\mathrm{K}, \mathrm{Rb}, \mathrm{Cs}, \mathrm{I}, \mathrm{Sn}$, and $\mathrm{Pb}$ and the $6-31 \mathrm{G}(\mathrm{d}, \mathrm{p})$ basis set for $\mathrm{Cl}$ and $\mathrm{Br}$, using the Gaussian 16 code (Revision b.01).

The Förster energy-transfer rates were calculated using the equation $k_{\text {Förster }}=\frac{2 \pi}{\hbar} V_{\mathrm{EET}}{ }^{2} J,{ }^{38,39}$ where $V_{\mathrm{EET}}$ is the electronic coupling for excitation energy transfer between the $\left[\mathrm{PbX}_{6}\right]^{4-}$ donor and the $\left[\mathrm{SnX}_{6}\right]^{4-}$ acceptor and $J$ is the normalized spectral overlap between the donor emission and acceptor absorption spectra. The electronic couplings $V$ for excitation energy transfer were calculated with the same functional and basis set as implemented in the Gaussian 16 code (Revision b.01).

Self-Trapped Emission Calculations. We calculated the selftrapped emissions of $\mathrm{OD}$ perovskites following the theory of luminescence described in refs $30,31,40$, and 41 , where the normalized luminescence line shape and intensity can be described as $G(\hbar \omega)=C \omega^{3} A(\hbar \omega)$, where $C^{-1}=\int A(\hbar \omega) \omega^{3} \mathrm{~d}(\hbar \omega)$ (C is the normalization factor, $\hbar \omega$ is the photon energy, and the " 3 " stands for the dipole-allowed transition); $A(\hbar \omega)$ is the normalized spectral function:

$$
A(\hbar \omega)=\sum_{m, n} w_{m}(T)\left|\left\langle\chi_{\mathrm{e} m} \mid \chi_{\mathrm{g} n}\right\rangle\right|^{2} \times \delta\left(E_{\mathrm{ZPL}}+\hbar \omega_{\mathrm{e} m}-\hbar \omega_{\mathrm{g} n}-\hbar \omega\right)
$$

where $w_{\mathrm{m}}(T)$ is the excited-state thermal occupation, $\chi_{\mathrm{g} n}$ and $\chi_{\mathrm{em}}$ are the ground-state and excited-state ionic wave functions, respectively, $E_{\mathrm{ZPL}}$ is the energy of the zero-phonon line, and $\hbar \omega_{\mathrm{em}}$ and $\hbar \omega_{\mathrm{gn}}$ are the excited-state and ground-state phonon energies, respectively. By assuming that the electronic transition dipole moments are independent of ionic coordinates, the Franck-Condon factor $\left(\left|\left\langle\chi_{\mathrm{em}} \mid \chi_{\mathrm{g} n}\right\rangle\right|\right)$ can be calculated by using the recurrence method. ${ }^{42}$

The broad band emissions were described by the one-dimensional (1D) configuration coordinate diagrams, ${ }^{40,41}$ including the parameters of the modal mass $M$, the displacement of the potential energy minima $\Delta R$, and the effective frequencies $\Omega_{\mathrm{g}}$ and $\Omega_{\mathrm{e}}$. The HuangRhys (HR) factors, defined as $S_{\mathrm{g}}=\Delta E_{\mathrm{g}} / \hbar \Omega_{\mathrm{g}}$ and $S_{\mathrm{e}}=\Delta E_{\mathrm{e}} / \hbar \Omega_{\mathrm{e}}{ }^{43}$ are used to describe the average number of phonons emitted during the optical transition and to evaluate how strongly electrons couple to phonons.

We calculated the broad band emissions of OD perovskites using the following strategy: We consider the octahedral shrinkage due to photoexcitation (i.e., the reduction of all six $\mathrm{Pb}(\mathrm{Sn})-\mathrm{X}$ bond lengths in the octahedra) as responsible for the generation of self-trapped states; then the $1 \mathrm{D}$ configuration coordinate diagram was built by linearly interpolating the coordinates between the neutral state and the self-trapped state. The coordinate difference between these two configurations is defined as $\Delta Q=\sqrt{\sum_{\kappa, i} M_{\kappa}\left(R_{\kappa, i}^{\mathrm{e}}-R_{\kappa, i}^{\mathrm{g}}\right)^{2}}$, where $M$ is the modal mass of each atom and $R_{\kappa, i}^{\mathrm{g}}$ and $R_{\kappa, i}^{\mathrm{e}}$ are the atomic coordinates for the ground and excited states, respectively. The coordinate $Q$ was linearly interpolated between 0 and $\Delta Q$. The phonon frequencies $\Omega_{\mathrm{g}}$ and $\Omega_{\mathrm{e}}$ were obtained by polynomial fitting of the ground-state or excited-state coordinate curves. The details of the calculations of the Franck-Condon factors and luminescence spectrum can be found in refs 30 and 31 and the computational codes in ref 44 . Note that we have included spin-orbit coupling (SOC) to calculate the total energies of both ground-state and selftrapped states. The underestimated band gaps arising from SOC were corrected according to the values obtained at the GGA/PBE level. The fitted broadening parameters were used to reproduce the experimental broad band emissions. 
(a)

$\mathrm{A}_{4} \mathrm{PbX}_{6}(\mathrm{~A}=\mathrm{K}, \mathrm{Rb}, \mathrm{Cs}, \mathrm{X}=\mathrm{Cl}, \mathrm{Br}, \mathrm{l})$
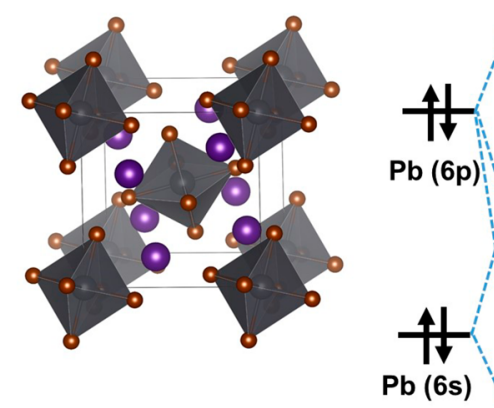

(b)

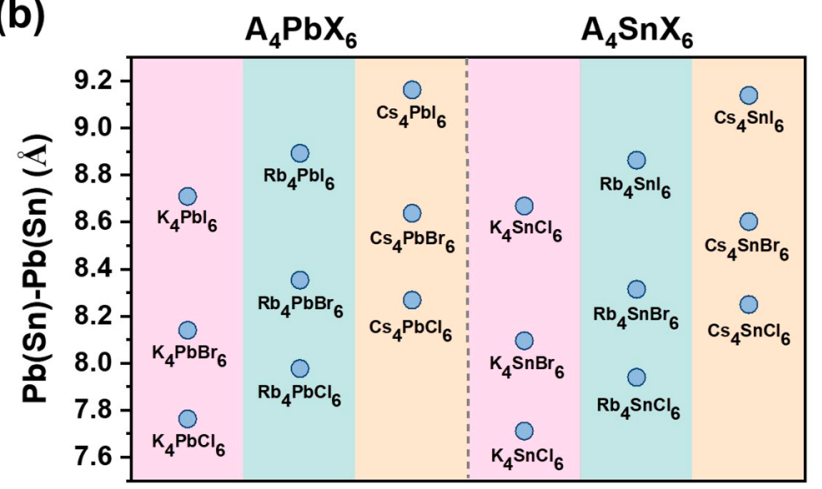

$\mathrm{A}_{4} \operatorname{SnX}_{6}(\mathrm{~A}=\mathrm{K}, \mathrm{Rb}, \mathrm{Cs}, \mathrm{X}=\mathrm{Cl}, \mathrm{Br}, \mathrm{I})$

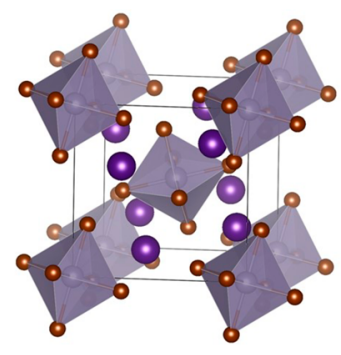

(c)

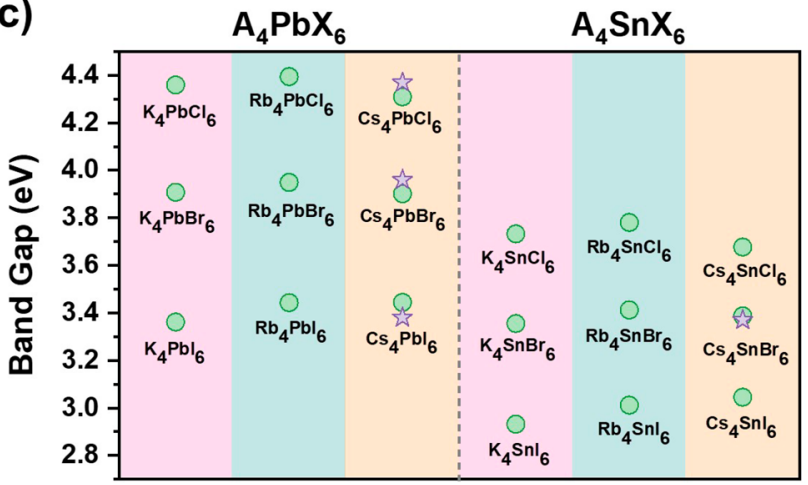

Figure 1. (a) Crystal structures of $\mathrm{A}_{4} \mathrm{PbX}_{6}$ and $\mathrm{A}_{4} \mathrm{SnX} \mathrm{X}_{6}(\mathrm{~A}=\mathrm{K}, \mathrm{Rb}$, and $\mathrm{Cs} ; \mathrm{X}=\mathrm{Cl}, \mathrm{Br}$, and I) together with the schematics of the orbital hybridization between $\mathrm{Pb}(\mathrm{Sn})$ and $\mathrm{X}$ atoms; $(\mathrm{b}) \mathrm{Pb}(\mathrm{Sn})-\mathrm{Pb}(\mathrm{Sn})$ distances between neighboring octahedra obtained from the crystal structures of $\mathrm{A}_{4} \mathrm{PbX}_{6}$ and $\mathrm{A}_{4} \mathrm{SnX}_{6}$ optimized at the GGA/PBE level; and (c) band gaps of $\mathrm{A}_{4} \mathrm{PbX}_{6}$ and $\mathrm{A}_{4} \mathrm{SnX}_{6}$ as calculated at the GGA/PBE level (the electronic band structures are shown in Figures $\mathrm{S} 1$ and $\mathrm{S} 2$, and the available experimental band gaps are shown with stars for comparison).

\section{RESULTS AND DISCUSSION}

The $\mathrm{A}_{4} \mathrm{PbX}_{6}$ and $\mathrm{A}_{4} \mathrm{SnX}$ compounds exhibit the same crystal structure (trigonal phase, $R \overline{3} c$ space group), where the individual $\left[\mathrm{PbX}_{6}\right]^{4-}$ and $[\mathrm{SnX}]^{4-}$ octahedra are separated by $\mathrm{Cs}^{+}$cations (see Figure 1a). The schematic diagram of orbital hybridization indicates that the valence band maximum (VBM) of $\mathrm{A}_{4} \mathrm{PbX}_{6}$ and $\mathrm{A}_{4} \mathrm{SnX}_{6}$ is composed of both the $6 s(5 s)$ orbital of the $\mathrm{Pb}(\mathrm{Sn})$ atoms and $\mathrm{p}$ orbitals of the halide atoms $(\mathrm{Cl} \mathrm{3p,} \mathrm{Br} \mathrm{4p,} \mathrm{and} \mathrm{I} \mathrm{5p).} \mathrm{The} \mathrm{conduction} \mathrm{band}$ minimum (CBM), on the other hand, mostly comes from $\mathrm{Pb}(\mathrm{Sn}) 6 \mathrm{p}(5 \mathrm{p})$ orbitals.

From an optimization of the crystal structures of the $0 \mathrm{D}$ perovskites, the $\mathrm{Pb}-\mathrm{Pb}$ and $\mathrm{Sn}-\mathrm{Sn}$ distances between neighboring octahedra are seen to vary upon tuning the Asite cations or halide atomic radii. As expected, the crystal lattice parameters show the same evolution, in the order $\mathrm{K}_{4} \mathrm{~Pb}(\mathrm{Sn}) \mathrm{X}_{6}<\mathrm{Rb}_{4} \mathrm{~Pb}(\mathrm{Sn}) \mathrm{X}_{6}<\mathrm{Cs}_{4} \mathrm{~Pb}(\mathrm{Sn}) \mathrm{X}_{6}$ and $\mathrm{A}_{4} \mathrm{~Pb}(\mathrm{Sn}) \mathrm{Cl}_{6}$ $<\mathrm{A}_{4} \mathrm{~Pb}(\mathrm{Sn}) \mathrm{Br}_{6}<\mathrm{A}_{4} \mathrm{~Pb}(\mathrm{Sn}) \mathrm{I}_{6}$ (Table S1). Overall, the $\mathrm{Pb}-\mathrm{Pb}$ and $\mathrm{Sn}-\mathrm{Sn}$ distances between neighboring octahedra range between 7.6 and $9.2 \AA$ (see Figure 1b).

From the calculated band structures of $\mathrm{A}_{4} \mathrm{PbX}_{6}$ and $\mathrm{A}_{4} \mathrm{SnX}_{6}$ (Figures $\mathrm{S} 1$ and $\mathrm{S} 2$ ), we find that (i) the band gaps of all $\mathrm{A}_{4} \mathrm{~Pb}(\mathrm{Sn}) \mathrm{X}_{6}$ compounds are significantly larger than those of their $3 \mathrm{D}$ and $2 \mathrm{D}$ counterparts $\left(\mathrm{APb}(\mathrm{Sn}) \mathrm{X}_{3}\right.$ and $\left.\mathrm{A}_{2} \mathrm{~Pb}(\mathrm{Sn}) \mathrm{X}_{5}\right)$ because of the weak orbital couplings between the octahedra, (ii) most of the $0 \mathrm{D}$ perovskites show an indirect band gap nature except for $\mathrm{Cs}_{4} \mathrm{PbBr}_{6}, \mathrm{Cs}_{4} \mathrm{PbI}_{6}$, and $\mathrm{Cs}_{4} \mathrm{SnI}_{6}$ despite the crystal structure similarities, (iii) the band gaps of $\mathrm{A}_{4} \mathrm{PbX}_{6}$ (which range between 3.4 and $4.4 \mathrm{eV}$ ) are larger than those of $\mathrm{A}_{4} \mathrm{SnX}_{6}$ (between 3.0 and $3.8 \mathrm{eV}$ ), and (iv) the band gaps of $\mathrm{A}_{4} \mathrm{~Pb}(\mathrm{Sn}) \mathrm{X}_{6}$ remain close (within $0.2 \mathrm{eV}$ ) when tuning the A- site cation while keeping the same halide atoms, whereas the band gap decreases when tuning only the halide atom $\left[\mathrm{A}_{4} \mathrm{~Pb}(\mathrm{Sn}) \mathrm{Cl}_{6}>\mathrm{A}_{4} \mathrm{~Pb}(\mathrm{Sn}) \mathrm{Br}_{6}>\mathrm{A}_{4} \mathrm{~Pb}(\mathrm{Sn}) \mathrm{I}_{6}\right]$. Therefore, the experimentally observed broad band emissions of $\mathrm{A}_{4} \mathrm{PbX}_{6}$ and $\mathrm{A}_{4} \mathrm{SnX} \mathrm{X}_{6}$ compounds can be attributed to intraband self-trapped states, as previously suggested rather than simple band-to-band recombination. ${ }^{8,24,43}$

In $\mathrm{OD}$ inorganic perovskites, the photogenerated charge carriers are generally confined within one unit cell and interact with the crystal lattice, which results in enhanced electronphonon couplings to form self-trapped excitons, as well as holes or electrons. ${ }^{4,46}$ As shown in Figure 2a, upon photoexcitation, the contraction of $\left[\mathrm{PbX}_{6}\right]^{4-}$ and $\left[\mathrm{SnX}_{6}\right]^{4-}$ octahedra (i.e., the six $\mathrm{Pb}-\mathrm{X}$ or $\mathrm{Sn}-\mathrm{X}$ bond lengths shorten) facilitates the stabilization of a hole trapped at the $\mathrm{Pb}$ or $\mathrm{Sn}$ site, forming the self-trapped charged states $\left(\left[\mathrm{PbBr}_{6}\right]^{4-} \rightarrow\right.$ $\left[\mathrm{PbBr}_{6}\right]^{3-}$ or $\left.\left[\mathrm{SnBr}_{6}\right]^{4-} \rightarrow\left[\mathrm{SnBr}_{6}\right]^{3-}\right) .{ }^{47}$ Hence, a photogenerated hole tends to be self-trapped in an octahedron and then captures the surrounding electron via Coulombic attraction to form the self-trapped exciton (STE). ${ }^{48,49}$ It is worth noting that our proposed self-trapped state involves octahedral contraction, which is different from the JahnTeller-like model that has been reported previously. ${ }^{43,50}$ The crystal structures for the self-trapped state were built by manually introducing local structural distortions to mimic light perturbation, that is, tuning the $\mathrm{Pb}(\mathrm{Sn})-\mathrm{Br}$ bond lengths or $\mathrm{Pb}(\mathrm{Sn})-\mathrm{Br}-\mathrm{Pb}(\mathrm{Sn})$ bond angles of central octahedra (Figure S3). In the case of $\mathrm{Cs}_{4} \mathrm{PbBr}_{6}$ and $\mathrm{Cs}_{4} \mathrm{SnBr}_{6}$, the $\mathrm{Pb}(\mathrm{Sn})-\mathrm{Br}$ bond lengths reduce by $5.9 \%$ in going from the ground state to the self-trapped state when we set the calculated band gaps of the self-trapped state to match the experimental emission band 

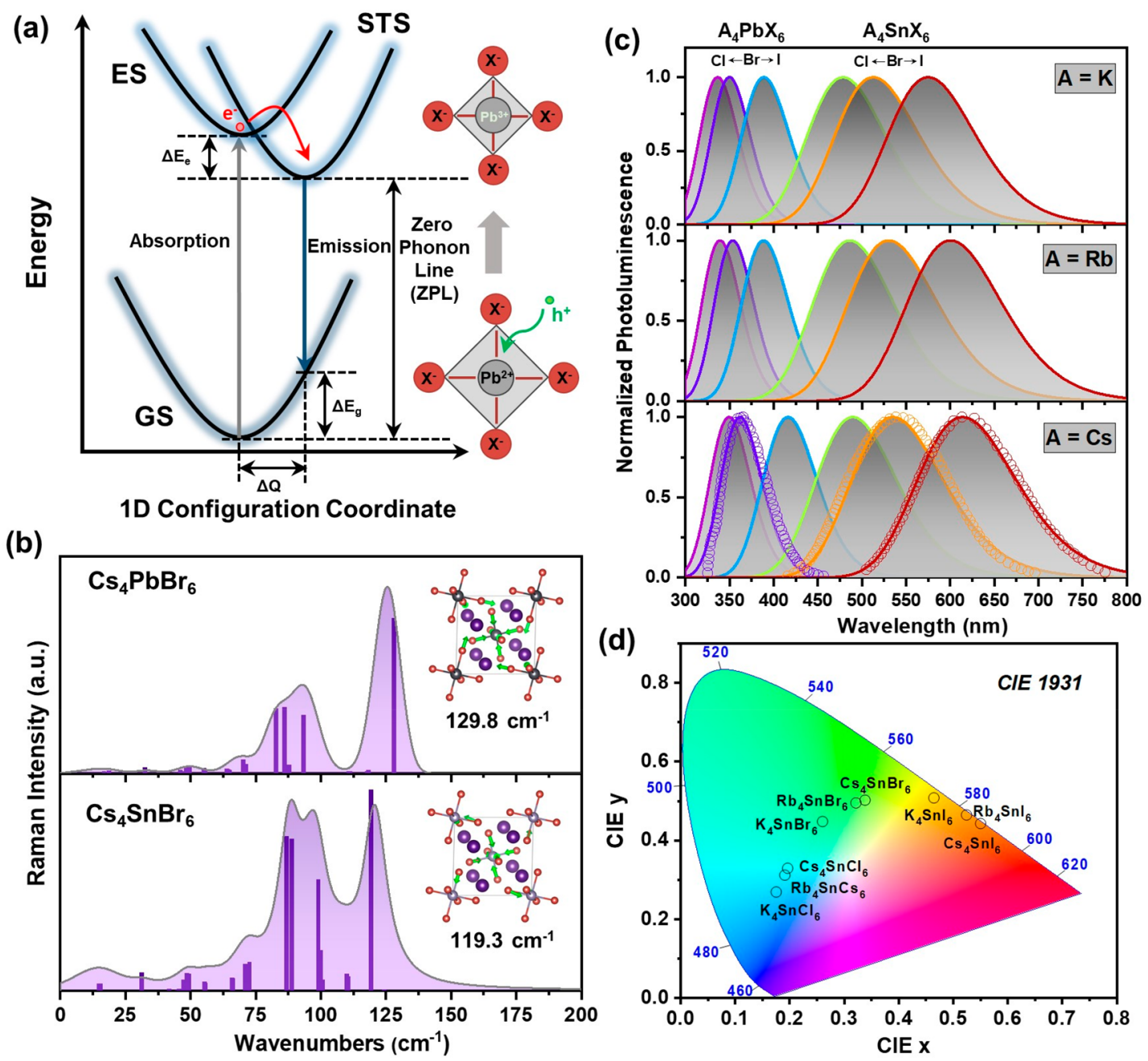

Figure 2. (a) One-dimensional (1D) configuration coordinate diagram of optical absorptions and self-trapped emissions of 0D perovskites together with an illustration of octahedra transitioning from the ground state (GS) to a charged self-trapped state due to photoexcitation (i.e., $\left[\mathrm{PbX}_{6}\right]^{4-} \rightarrow$ $\left[\mathrm{PbX}_{6}\right]^{3-}$ or $\left[\mathrm{SnX}_{6}\right]^{4-} \rightarrow\left[\mathrm{SnX}_{6}\right]^{3-}, \mathrm{X}=\mathrm{Cl}, \mathrm{Br}$, and I); (b) calculated Raman spectra of $\mathrm{Cs}_{4} \mathrm{PbBr}_{6}$ and $\mathrm{Cs}_{4} \mathrm{SnBr}_{6}$ and illustration of selected vibrational normal modes (the displacement vectors are indicated by green arrows); (c) self-trapped PL spectra (the available experimental PL spectra of $\mathrm{Cs}_{4} \mathrm{PbBr}_{6}, \mathrm{Cs}_{4} \mathrm{SnBr}_{6}$, and $\mathrm{Cs}_{4} \mathrm{SnI}_{6}$ are plotted with open circles); and (d) corresponding CIE diagrams for $\mathrm{A}_{4} \mathrm{PbX}_{6}$ and $\mathrm{A}_{4} \mathrm{SnX} \mathrm{X}_{6}(\mathrm{~A}=\mathrm{K}$, $\mathrm{Rb}$, and $\mathrm{Cs}$, and $\mathrm{X}=\mathrm{Cl}, \mathrm{Br}$, and I), as calculated at the GGA/PBE level with consideration of spin-orbit coupling (SOC) effects.

maxima (i.e., $3.4 \mathrm{eV}$ for $\mathrm{Cs}_{4} \mathrm{PbBr}_{6}$ and $2.3 \mathrm{eV}$ for $\mathrm{Cs}_{4} \mathrm{SnBr}_{6}$; see Figure S3).

Such a photoexcitation-induced reduction in the $\mathrm{Pb}(\mathrm{Sn})-\mathrm{X}$ bond lengths is further supported by phonon modes corresponding to $\mathrm{Pb}(\mathrm{Sn})-\mathrm{X}$ stretching features (see the displacement vectors of the phonon mode at $119.3 \mathrm{~cm}^{-1}$ for $\mathrm{Cs}_{4} \mathrm{SnBr}_{6}$ and $129.8 \mathrm{~cm}^{-1}$ for $\mathrm{Cs}_{4} \mathrm{PbBr}_{6}$ in Figure $2 \mathrm{~b}$ and Figure S4). Note that we can exclude the formation of a negatively charged polaron state formed by two $\mathrm{Br}$ atoms (i.e., $\mathrm{Br}_{2}^{-}$), as the band gaps are away from the emission band maxima, upon tuning the $\mathrm{Br}-\mathrm{Pb}(\mathrm{Sn})-\mathrm{Br}$ angles from $90^{\circ}$ to $65^{\circ}$ (see Figure S3). Hence, on the one hand, the large electron-phonon coupling and the deformation of $\left[\mathrm{PbX}_{6}\right]^{4-}$ and $\left[\mathrm{SnX}_{6}\right]^{4-}$ octahedra become the first step in the generation of selftrapped states, which leads to broad band emissions in these OD inorganic perovskites; on the other hand, the dominant stretching phonon modes of $\mathrm{A}_{4} \mathrm{PbX}_{6}$ and $\mathrm{A}_{4} \mathrm{SnX} \mathrm{X}_{6}$ can assist self-trapped exciton recombination in $\left[\mathrm{PbX}_{6}\right]^{4-}$ and $\left[\mathrm{SnX}_{6}\right]^{4-}$ octahedra. $^{51}$

We now turn to the one-dimensional (1D) configuration coordinate diagram approach ${ }^{30,31}$ to describe the energetics of self-trapped states and simulate the broad band emissions of $0 \mathrm{D}$ inorganic perovskites. The $1 \mathrm{D}$ configuration coordinate diagrams of the ground and self-trapped excited states for the $\mathrm{A}_{4} \mathrm{PbX}_{6}$ and $\mathrm{A}_{4} \mathrm{SnX}_{6}$ compounds are given in Figures S5-S7. Overall, our methodology reproduces very well the experimental broad band emissions (see the comparisons of $\mathrm{Cs}_{4} \mathrm{PbBr}_{6}, \mathrm{Cs}_{4} \mathrm{SnBr}_{6}$, and $\mathrm{Cs}_{4} \mathrm{SnI}_{6}$ in Figure S8). Figure 2c,d show the calculated self-trapped exciton emission spectra and the corresponding $\mathrm{CIE}$ diagrams of $\mathrm{A}_{4} \mathrm{PbX}_{6}$ and $\mathrm{A}_{4} \mathrm{SnX} 6$ compounds. We find that the $\mathrm{A}_{4} \mathrm{PbX}_{6}$ compounds display broad band emissions between 300 and $500 \mathrm{~nm}$ with a fullwidth at half-maximum (fwhm) of $\sim 50-60 \mathrm{~nm}$, whereas the $\mathrm{A}_{4} \mathrm{SnX}_{6}$ compounds show broad band emissions between 400 and $800 \mathrm{~nm}$ with a much larger fwhm of $\sim 100-120 \mathrm{~nm}$. For $\mathrm{A}_{4} \mathrm{SnX}_{6}$, the emission color is tunable from blue to red through halide atom substitution, and emission becomes narrower when changing the halide atoms from $\mathrm{I}^{-}$to $\mathrm{Br}^{-}$and then $\mathrm{Cl}^{-}$. On the other hand, replacing the $\mathrm{Cs}^{+}$cations with $\mathrm{K}^{+}$or $\mathrm{Rb}^{+}$ leads to a blue shift of the emission maximum, which is in agreement with the experimental PL spectral change when the $\mathrm{Cs}^{+}$cations are partially substituted with $\mathrm{K}^{+}$or $\mathrm{Rb}^{+}$. 
(a)

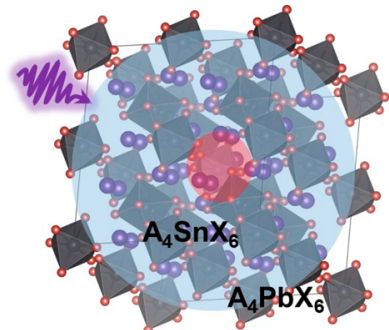

$\mathrm{A}_{4} \mathrm{PbX}_{6} / \mathrm{A}_{4} \mathrm{SnX} \mathrm{X}_{6}$ heterojunction

(b)

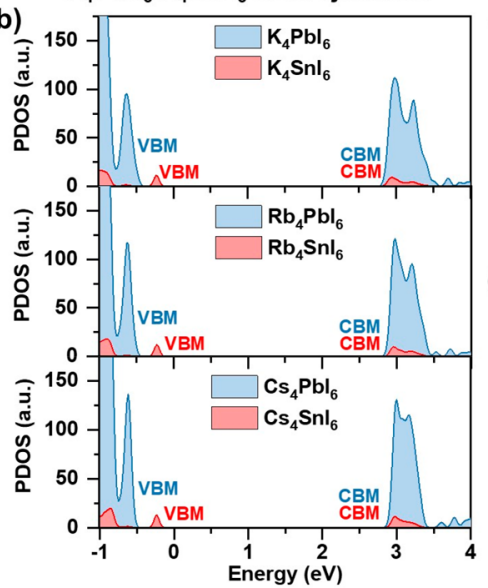

(c)

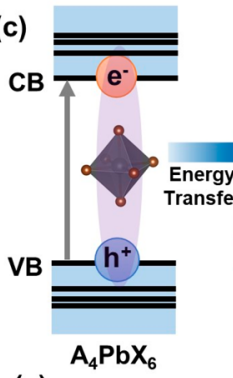

(e)

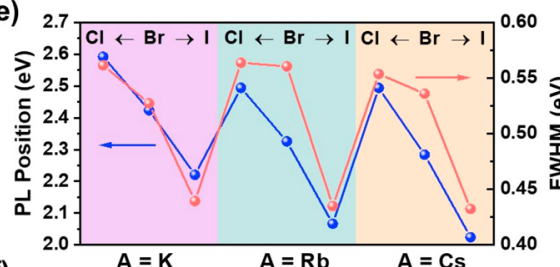

(f)

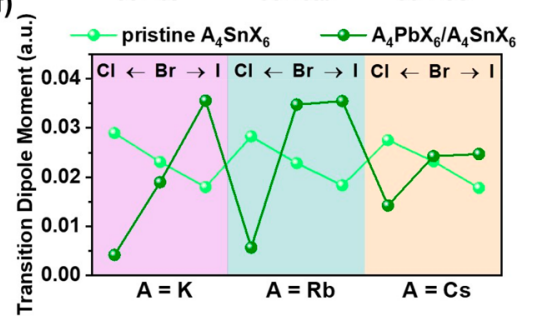

(d) $\square$ Absorption Spectra of $\mathrm{A}_{4} \mathrm{SnX}$

PL Spectra of $\mathrm{A}_{4} \mathrm{PbX}$

PL Spectra of APX-ASX heterojunction

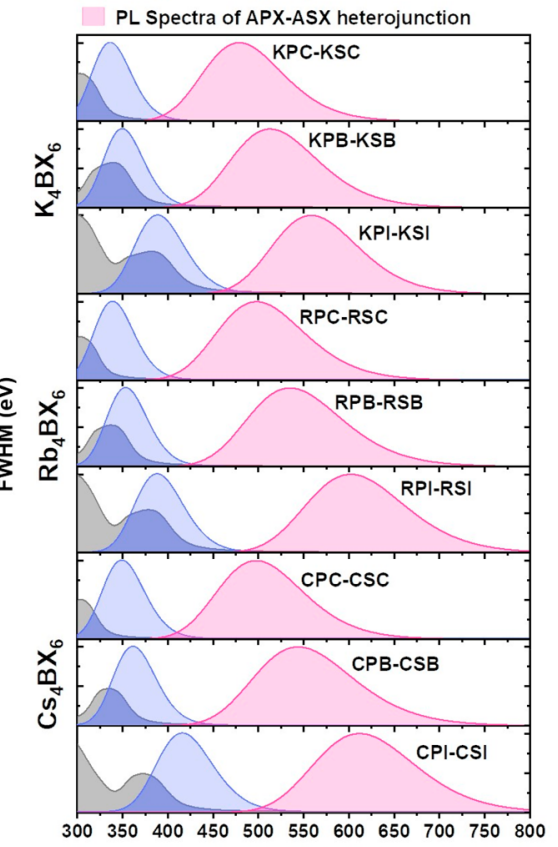

Wavelength $(\mathrm{nm})$

Figure 3. (a) Proposed bulk $\mathrm{A}_{4} \mathrm{PbX}_{6} / \mathrm{A}_{4} \mathrm{SnX}_{6}$ mixtures $(\mathrm{A}=\mathrm{K}, \mathrm{Rb}$, and $\mathrm{Cs} ; \mathrm{X}=\mathrm{Cl}, \mathrm{Br}$, and $\mathrm{I})$ obtained by replacing the central $\mathrm{A}_{4} \mathrm{PbX} 6$ octahedron with $\mathrm{A}_{4} \mathrm{SnX}_{6}$ in $2 \times 2 \times 2 \mathrm{~A}_{4} \mathrm{PbX}_{6}$ supercells; (b) calculated projected density of states (PDOS) for $\mathrm{A}_{4} \mathrm{PbX}_{6}$ and $\mathrm{A}_{4} \mathrm{SnX}_{6}$ in $\mathrm{A}_{4} \mathrm{PbX}_{6} / \mathrm{A}_{4} \mathrm{SnX} 6$ mixtures; (c) corresponding diagram of energy transfer from $\mathrm{A}_{4} \mathrm{PbX}_{6}$ octahedra to the central $\mathrm{A}_{4} \mathrm{SnX}_{6}$ octahedron; and (d) PL spectra of the selftrapped species; (e) calculated PL positions and full-width at half-maximum (fwhm); and (f) transition dipole moments of $\mathrm{A}_{4} \mathrm{PbX}_{6}$ and $\mathrm{A}_{4} \mathrm{SnX} \mathrm{X}_{6}(\mathrm{~A}$ $=\mathrm{K}, \mathrm{Rb}$, and $\mathrm{Cs} ; \mathrm{X}=\mathrm{Cl}, \mathrm{Br}$, and $\mathrm{I})$, as calculated at the GGA/PBE level with SOC effects.

After having reproduced the broad band emissions of a series of $0 \mathrm{D} \mathrm{A}_{4} \mathrm{PbX}_{6}$ and $\mathrm{A}_{4} \mathrm{SnX}$ inorganic perovskites, we now consider the design of bulk $\mathrm{A}_{4} \mathrm{PbX}_{6} / \mathrm{A}_{4} \mathrm{SnX}_{6}$ mixtures via the replacement of one of the $\mathrm{A}_{4} \mathrm{PbX}_{6}$ octahedra with $\mathrm{A}_{4} \mathrm{SnX}_{6}$ in a supercell model (see Figure $3 \mathrm{a}$ ). From the calculated projected density of states (PDOS) of such bulk $\mathrm{A}_{4} \mathrm{PbX}_{6} / \mathrm{A}_{4} \mathrm{SnX} 6$ mixtures, as shown in Figure $3 \mathrm{~b}$ and Figure $S 9$, we find that the energies of the conduction band minima (CBM) of $\mathrm{A}_{4} \mathrm{PbX}_{6}$ and $\mathrm{A}_{4} \mathrm{SnX}_{6}$ are almost aligned, whereas the valence band maximum (VBM) of $\mathrm{A}_{4} \mathrm{SnX}_{6}$ is above that of $\mathrm{A}_{4} \mathrm{PbX}_{6}$. Such a type-I energy level alignment is conducive to energy transfer to the central $\mathrm{A}_{4} \mathrm{SnX}_{6}$ from the surrounding $\mathrm{A}_{4} \mathrm{PbX}_{6}$ octahedra (Figure 3c). That this energy transfer can be efficient is also supported by the large spectral overlap between the absorption spectra of $\mathrm{A}_{4} \mathrm{SnX}_{6}$ (the calculated dielectric function is shown in Figures S10 and S11) and the emission spectra of $\mathrm{A}_{4} \mathrm{PbX}_{6}$ (Figure 3d).

In addition to the spectral overlap and Förster energy transfer, Dexter-type energy transfer could also occur due to some degree of wave function overlap between the lowest unoccupied molecular orbitals (LUMOs) of adjacent octahedra. ${ }^{38,39}$ As shown in Figure 4, for both $\left[\mathrm{PbCl}_{6}\right]^{4-} /\left[\mathrm{SnCl}_{6}\right]^{4-}$ and $\left[\mathrm{PbBr}_{6}\right]^{4-} /\left[\mathrm{SnBr}_{6}\right]^{4-}$ dimers (the distance between octahedra is less than $10 \AA$ ), the calculated Förster energytransfer rates are $10^{9}-10^{11} \mathrm{~s}^{-1}$ (on the same order of magnitude as those in molecular systems ${ }^{36}$ ) and are significantly higher than those occurring via a Dexter mechanism $\left(10^{8}-10^{9} \mathrm{~s}^{-1}\right)$. However, in $\left[\mathrm{PbI}_{6}\right]^{4-} /\left[\mathrm{SnI}_{6}\right]^{4-}$, Dexter energy transfer becomes prominent, with transfer rates of $10^{8}-10^{9} \mathrm{~s}^{-1}$ as compared to those via a Förster mechanism $\left(10^{6}-10^{7} \mathrm{~s}^{-1}\right)$, which is due to much larger electronic

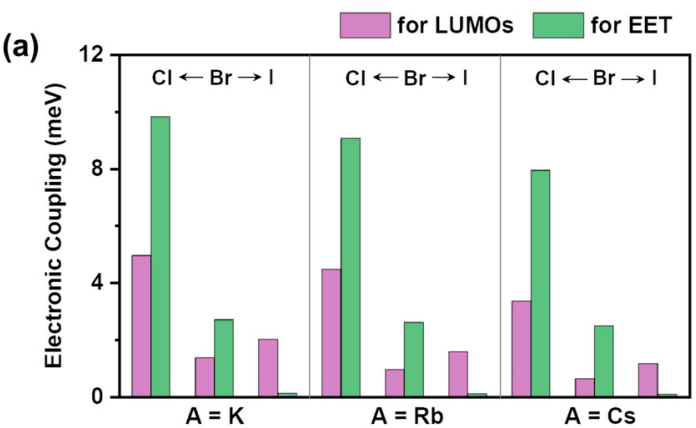

(b) $\square \operatorname{Dexter}(7-10 \AA) \square$ Förster (7-10 A) $\square$ Förster (15-20 A)

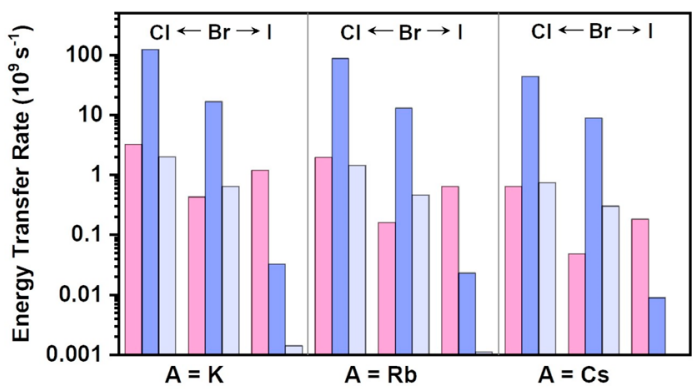

Figure 4. (a) Calculated electronic couplings between the lowest unoccupied molecular orbitals (LUMOs) and for excitation energy transfer (EET) between neighboring $\left[\mathrm{PbX}_{6}\right]^{4-}$ and $\left[\mathrm{SnX}_{6}\right]^{4-}$ octahedra; and (b) calculated Dexter and Förster energy-transfer rates from $\left[\mathrm{PbX}_{6}\right]^{4-}$ to $\left[\mathrm{SnX}_{6}\right]^{4-}$ octahedra. The calculations were performed at the CAM-B3LYP level with the LANL2DZ and 6$31 \mathrm{G}(\mathrm{d}, \mathrm{p})$ basis sets; the calculated parameters are given in Table S2. 


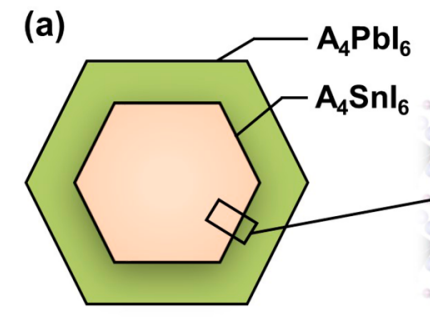

(b)

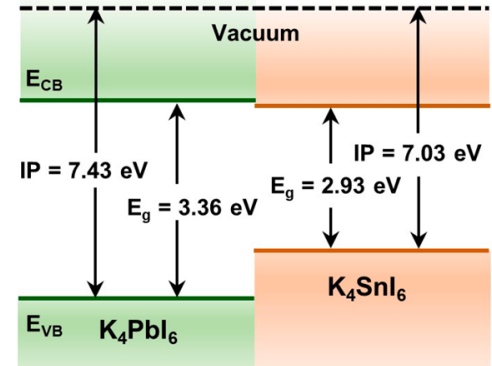

(c)

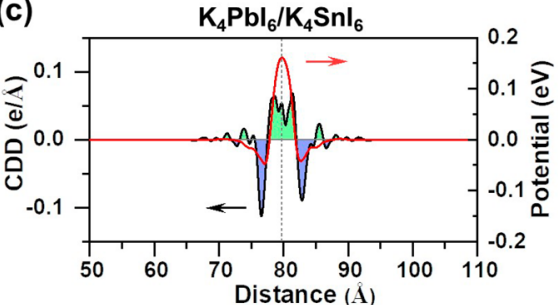

$\mathrm{A}_{4} \mathrm{Pbl}_{6} / \mathrm{A}_{4} \mathrm{SnI}_{6}$ Heterojunction

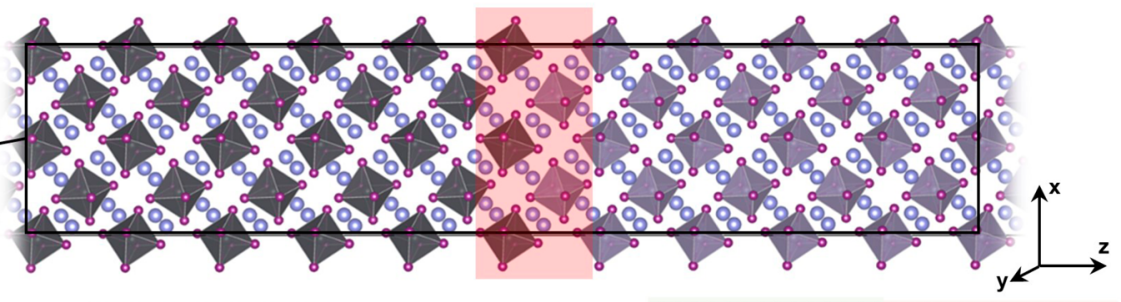

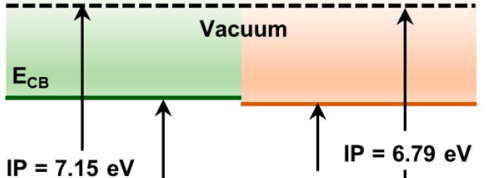

$\mathrm{IP}=7.15 \mathrm{eV}$

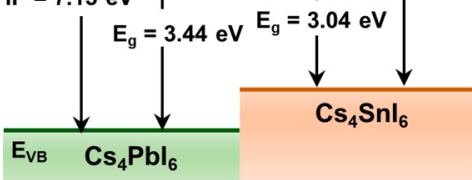

Figure 5. (a) Proposed core-shell nanocrystal structure with an $\mathrm{A}_{4} \mathrm{SnI}_{6}$ core and an $\mathrm{A}_{4} \mathrm{PbI}_{6}$ shell and corresponding crystal structure of the $\mathrm{A}_{4} \mathrm{SnI} \mathrm{I}_{6} /$ $\mathrm{A}_{4} \mathrm{PbI}_{6}$ heterojunction; (b) energy level alignments based on the calculated ionization potentials (IPs) and band gaps for $\mathrm{A}_{4} \mathrm{PbI}_{6} / \mathrm{A}_{4} \mathrm{SnI}_{6}$ heterojunctions; and (c) one-dimensional average planar charge density differences (CDDs), defined as $\Delta \rho=\rho\left(\mathrm{A}_{4} \mathrm{PbI}_{6} / \mathrm{A}_{4} \mathrm{SnI}_{6}\right)-\rho\left(\mathrm{A}_{4} \mathrm{PbI}_{6}\right)-$ $\rho\left(\mathrm{A}_{4} \mathrm{SnI}_{6}\right)$, and corresponding electrostatic potentials for $\mathrm{A}_{4} \mathrm{PbI}_{6} / \mathrm{A}_{4} \mathrm{SnI}_{6}$ heterojunctions (three-dimensional CDDs are shown in Figure S15). All calculations were performed at the GGA/PBE level of theory.

couplings for LUMOs than those for EET. At longer distances, in the range between 15 and $20 \AA$, the Förster energy transfer in $\left[\mathrm{PbCl}_{6}\right]^{4-} /\left[\mathrm{SnCl}_{6}\right]^{4-}$ and $\left[\mathrm{PbBr}_{6}\right]^{4-} /\left[\mathrm{SnBr}_{6}\right]^{4-}$ is dominant with transfer rates of $10^{8}-10^{9} \mathrm{~s}^{-1}$. Thus, strong spectral overlap and electronic coupling for excitation energy transfer between the $\left[\mathrm{PbX}_{6}\right]^{4-}$ and $\left[\mathrm{SnX}_{6}\right]^{4-}$ octahedra enable efficient resonant energy transfer, enhancing the self-trapped exciton emissions.

Interestingly, the bulk $\mathrm{A}_{4} \mathrm{PbX}_{6} / \mathrm{A}_{4} \mathrm{SnX}$ mixtures show the same broad features (Figure $3 \mathrm{e}$ ) and even larger transition dipole moments than those of pristine $\mathrm{A}_{4} \mathrm{SnX} \mathrm{X}_{6}$, especially in the case of mixtures containing $\mathrm{I}^{-}$(Figure $3 \mathrm{f}$ ). This result points to an efficient radiative recombination when $\mathrm{A}_{4} \mathrm{SnX}_{6}$ is located in the $\mathrm{A}_{4} \mathrm{PbX}_{6}$ lattice, owing to increased electronic couplings between the ground and self-trapped states (Figure S12) and reduced hole-trapping barriers (i.e., smaller energy differences between the excited state and the hole self-trapped state) in $0 \mathrm{D}$ heterostructures. Therefore, the combination of type-I energy level alignment with efficient energy transfer and increased transition dipoles enables an enhancement of the self-trapped emissions in the bulk $\mathrm{A}_{4} \mathrm{PbX}_{6} / \mathrm{A}_{4} \mathrm{SnX}_{6}$ mixtures as compared to those in pristine $\mathrm{A}_{4} \mathrm{SnX}_{6}$, which makes these systems promising new photoactive materials for white-light-emission applications.

In addition to the bulk $\mathrm{A}_{4} \mathrm{PbX}_{6} / \mathrm{A}_{4} \mathrm{SnX} 6$ mixtures where $\left[\mathrm{SnX}_{6}\right]^{4-}$ octahedra are inserted into the $\left[\mathrm{PbX}_{6}\right]^{4-}$ matrix, we considered the design of $\mathrm{A}_{4} \mathrm{SnX}_{6} / \mathrm{A}_{4} \mathrm{PbX}_{6}$ heterojunctions formed by an $\mathrm{A}_{4} \mathrm{SnX} 6$ core and an $\mathrm{A}_{4} \mathrm{PbX}_{6}$ shell. In these structures, the emissive $\left[\mathrm{SnX}_{6}\right]^{4-}$ centers are completely protected by the $\mathrm{A}_{4} \mathrm{PbX}_{6}$ shells, which have been experimentally shown to exhibit good photostability in ambient conditions. ${ }^{2}$ This will inhibit oxidation, that is, transformation from $\left[\mathrm{SnI}_{6}\right]^{4-}$ to $\left[\mathrm{SnX}_{6}\right]^{2-}$, upon air exposure. The heterojunction models were constructed by aligning $\mathrm{A}_{4} \mathrm{SnI}_{6}$ and $\mathrm{A}_{4} \mathrm{PbI}_{6}$ octahedra along the (001) direction (the lattice mismatch is less than $0.3 \%$ ), as shown in Figure 5a. Optimization of the $\mathrm{A}_{4} \mathrm{SnI}_{6} / \mathrm{A}_{4} \mathrm{PbI}_{6}$ heterojunctions shows that the $\left[\mathrm{PbI}_{6}\right]^{4-}$ and $\left[\mathrm{SnI}_{6}\right]^{4-}$ octahedra at the interfacial region retain their bulk orientations without any rotation or distortion. From the calculated PDOS of the $\mathrm{A}_{4} \mathrm{SnI}_{6} / \mathrm{A}_{4} \mathrm{PbI}_{6}$ heterojunctions (Figure S13), we find that both the VBM and $\mathrm{CBM}$ of $\mathrm{A}_{4} \mathrm{SnI}_{6}$ are contained within the $\mathrm{A}_{4} \mathrm{PbI}_{6}$ gap; again, such a type-I alignment character can promote energy transfer from the $\mathrm{A}_{4} \mathrm{PbI}_{6}$ shell to the $\mathrm{A}_{4} \mathrm{SnI}_{6}$ core. This is further confirmed by the energy level alignments of $\mathrm{A}_{4} \mathrm{PbI}_{6} / \mathrm{A}_{4} \mathrm{SnI}_{6}$ heterojunctions on the basis of the calculated band gaps, ionization potentials, and average electrostatic potentials (Figure S14), which show small conduction band offsets (less than $0.1 \mathrm{eV}$ ) and somewhat larger valence band offsets; see Figure $5 \mathrm{~b}$. Moreover, similar to the case of $\mathrm{A}_{4} \mathrm{SnI}_{6} / \mathrm{A}_{4} \mathrm{PbI}_{6}$ mixtures, the interfacial $\left[\mathrm{PbX}_{6}\right]^{4-}$ and $\left[\mathrm{SnX}_{6}\right]^{4-}$ species (highlighted by the red area in Figure 5a) can also be considered as octahedral dimers with efficient EET.

We also estimated the electronic charge rearrangements upon formation of $\mathrm{A}_{4} \mathrm{PbI}_{6} / \mathrm{A}_{4} \mathrm{SnI}_{6}$ heterojunctions by examining the one-dimensional plane-averaged charge density differ- 
ences along the $z$-direction (black lines in Figure $5 \mathrm{c}$ ); these are defined as $\Delta \rho=\rho\left(\mathrm{A}_{4} \mathrm{PbI}_{6} / \mathrm{A}_{4} \mathrm{SnI}_{6}\right)-\rho\left(\mathrm{A}_{4} \mathrm{PbI}_{6}\right)-\rho\left(\mathrm{A}_{4} \mathrm{SnI}_{6}\right)$. The $\mathrm{A}_{4} \mathrm{PbI}_{6} / \mathrm{A}_{4} \mathrm{SnI}_{6}$ heterojunctions exhibit similar charge rearrangement features at the interfaces, with the hole $(\Delta \rho<0$, blue area) and electron $(\Delta \rho>0$, green area) accumulation layers appearing in an alternate fashion on each $\mathrm{A}_{4} \mathrm{PbI}_{6}$ and $\mathrm{A}_{4} \mathrm{SnI}_{6}$ side. Such a charge rearrangement leads to a large potential barrier $\left(0.209 \mathrm{eV}\right.$ in $\mathrm{K}_{4} \mathrm{PbI}_{6} / \mathrm{K}_{4} \mathrm{SnI}_{6}, 0.177 \mathrm{eV}$ in $\mathrm{Rb}_{4} \mathrm{PbI}_{6} / \mathrm{Rb}_{4} \mathrm{SnI}_{6}$, and $0.154 \mathrm{eV}$ in $\mathrm{Cs}_{4} \mathrm{PbI}_{6} / \mathrm{Cs}_{4} \mathrm{SnI}_{6}$; see red lines in Figure $5 \mathrm{c}$ ), which prevents charge transfer across the interface but allows hole trapping at interfacial $\left[\mathrm{PbX}_{6}\right]^{4-} /$ $\left[\mathrm{SnX}_{6}\right]^{4-}$ octahedra; subsequent structural deformations result in the formation of self-trapped excitons.

\section{CONCLUSIONS}

A characterization of their parent $0 \mathrm{D}$ perovskite compounds has led to the design of two types of $\mathrm{A}_{4} \mathrm{PbX}_{6} / \mathrm{A}_{4} \mathrm{SnX} \mathrm{X}_{6}$ OD inorganic perovskite heterostructures, bulk mixtures, and heterojunctions. We systematically explored the electronic structures and optical properties of these heterostructures by means of DFT calculations.

On the basis of the 1D configuration coordinate diagram approach, we determined the presence of self-trapped emissions in both the pristine $0 \mathrm{D}$ perovskites and $\mathrm{A}_{4} \mathrm{PbX}_{6} /$ $\mathrm{A}_{4} \mathrm{SnX}_{6}$ heterostructures. We found that the $\mathrm{A}_{4} \mathrm{PbX}_{6} / \mathrm{A}_{4} \mathrm{SnX} 6$ bulk mixtures and heterojunctions show type-I energy level alignment and large spectral overlap, which results in efficient energy transfer and increased transition dipole moments. Our work points to new promising low-dimensional systems for highly efficient white-light-emission applications.

\section{ASSOCIATED CONTENT}

\section{SI Supporting Information}

The Supporting Information is available free of charge at https://pubs.acs.org/doi/10.1021/acs.chemmater.0c00658.

Computational methods, optimized crystallographic parameters, dielectric function, 1D configuration coordinate diagram, and projected density of states and charge density differences for $\mathrm{A}_{4} \mathrm{PbX}_{6}$ and $\mathrm{A}_{4} \mathrm{SnX}_{6}$ compounds and bulk $\mathrm{A}_{4} \mathrm{PbX}_{6} / \mathrm{A}_{4} \mathrm{SnX}_{6}$ mixtures ( $\mathrm{PDF}$ )

\section{AUTHOR INFORMATION}

\section{Corresponding Authors}

Omar F. Mohammed - Division of Physical Science and Engineering, King Abdullah University of Science and Technology, Thuwal 23955-6900, Kingdom of Saudi Arabia; (1) orcid.org/0000-0001-8500-1130;

Email: omar.abdelsaboor@kaust.edu.sa

Osman M. Bakr - Division of Physical Science and Engineering, King Abdullah University of Science and Technology, Thuwal

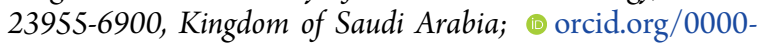
0002-3428-1002; Email: osman.bakr@kaust.edu.sa

Jean-Luc Brédas - Department of Chemistry and Biochemistry, The University of Arizona, Tucson, Arizona 85721-0088, United States; (1) orcid.org/0000-0001-7278-4471; Email: jlbredas@email.arizona.edu

\section{Author}

Jun Yin - Division of Physical Science and Engineering, King Abdullah University of Science and Technology, Thuwal 23955-

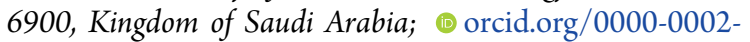
1749-1120
Complete contact information is available at:

https://pubs.acs.org/10.1021/acs.chemmater.0c00658

\section{Notes}

The authors declare no competing financial interest.

\section{ACKNOWLEDGMENTS}

This work was supported by the King Abdullah University of Science and Technology (KAUST) and the College of Science of the University of Arizona. We acknowledge the Supercomputing Laboratory at KAUST for their computational and storage resources, as well as their efficient technical assistance.

\section{REFERENCES}

(1) Xu, J. W.; Huang, W. X.; Li, P. Y.; Onken, D. R.; Dun, C. C.; Guo, Y.; Ucer, K. B.; Lu, C.; Wang, H. Z.; Geyer, S. M.; et al. Imbedded Nanocrystals of $\mathrm{Cs} \mathrm{PbBr}_{3}$ in $\mathrm{Cs}_{4} \mathrm{PbBr}_{6}$ : Kinetics, Enhanced Oscillator Strength, and Application in Light-Emitting. Adv. Mater. 2017, 29, 1703703.

(2) Bao, Z.; Wang, H. C.; Jiang, Z. F.; Chung, R. J.; Liu, R. S. Continuous Synthesis of Highly Stable $\mathrm{Cs}_{4} \mathrm{PbBr}_{6}$ Perovskite Microcrystals by a Microfluidic System and Their Application in WhiteLight-Emitting Diodes. Inorg. Chem. 2018, 57, 13071-13074.

(3) Sun, X.; Gao, Z.; Liu, Y.; Wang, Z.; Wang, X.; Zhang, W.; Xu, B.; Meng, X. Lasing from Zero-Dimensional Perovskite and Optical Imaging Applications. ACS Photonics 2019, 6, 3290-3297.

(4) Tong, G. Q.; Li, H.; Zhu, Z. F.; Zhang, Y.; Yu, L. W.; Xu, J.; Jiang, Y. Enhancing Hybrid Perovskite Detectability in the Deep Ultraviolet Region with Down-Conversion Dual-Phase $\left(\mathrm{CsPbBr}_{3}\right.$ $\mathrm{Cs}_{4} \mathrm{PbBr}_{6}$ ) Films. J. Phys. Chem. Lett. 2018, 9, 1592-1599.

(5) Cha, J. H.; Han, J. H.; Yin, W.; Park, C.; Park, Y.; Ahn, T. K.; Cho, J. H.; Jung, D. Y. Photoresponse of $\mathrm{CsPbBr}_{3}$ and $\mathrm{Cs}_{4} \mathrm{PbBr}_{6}$ Perovskite Single Crystals. J. Phys. Chem. Lett. 2017, 8, 565-570.

(6) Yakunin, S.; Benin, B. M.; Shynkarenko, Y.; Nazarenko, O.; Bodnarchuk, M. I.; Dirin, D. N.; Hofer, C.; Cattaneo, S.; Kovalenko, M. V. High-Resolution Remote Thermometry and Thermography Using Luminescent Low-Dimensional Tin-Halide Perovskites. Nat. Mater. 2019, 18, 846-852.

(7) Zhao, H. G.; Sun, R. J.; Wang, Z. F.; Fu, K. F.; Hu, X.; Zhang, Y. H. Zero-Dimensional Perovskite Nanocrystals for Efficient Luminescent Solar Concentrators. Adv. Funct. Mater. 2019, 29, 1902262.

(8) Benin, B. M.; Dirin, D. N.; Morad, V.; Worle, M.; Yakunin, S.; Raino, G.; Nazarenko, O.; Fischer, M.; Infante, I.; Kovalenko, M. V. Highly Emissive Self-Trapped Excitons in Fully Inorganic ZeroDimensional Tin Halides. Angew. Chem., Int. Ed. 2018, 57, 1132911333.

(9) Savchyn, P. V.; Myagkota, S. V.; Voloshinovskii, A. S.; Demkiv, T. M.; Datsjuk, J. R. Luminescent Properties of Sn-Based Microcrystals Embedded in CsBr Matrix. Radiat. Meas. 2007, 42, 697-700.

(10) Zhou, C. K.; Tian, Y.; Yuan, Z.; Lin, H. R.; Chen, B. H.; Clark, R.; Dilbeck, T.; Zhou, Y.; Hurley, J.; Neu, J.; et al. Highly Efficient Broadband Yellow Phosphor Based on Zero-Dimensional Tin MixedHalide Perovskite. ACS Appl. Mater. Interfaces 2017, 9, 44579-44583.

(11) Zhou, C. K.; Lin, H. R.; Tian, Y.; Yuan, Z.; Clark, R.; Chen, B. H.; van de Burgt, L. J.; Wang, J. C.; Zhou, Y.; Hanson, K.; et al. Luminescent Zero-Dimensional Organic Metal Halide Hybrids with Near-unity Quantum Efficiency. Chem. Sci. 2018, 9, 586-593.

(12) Yin, J.; Zhang, Y. H.; Bruno, A.; Soci, C.; Bakr, O. M.; Bredas, J. L.; Mohammed, O. F. Intrinsic Lead Ion Emissions in ZeroDimensional $\mathrm{Cs}_{4} \mathrm{PbBr}_{6}$ Nanocrystals. ACS Energy Lett. 2017, 2, 2805-2811.

(13) Arunkumar, P.; Cho, H. B.; Gil, K. H.; Unithrattil, S.; Kim, Y. H.; Bin Im, W. Probing Molecule-Like Isolated Octahedra via Phase Stabilization of Zero-Dimensional Cesium Lead Halide Nanocrystals. Nat. Commun. 2018, 9, 4691. 
(14) Yin, J.; Maity, P.; De Bastiani, M.; Dursun, I.; Bakr, O. M.; Bredas, J. L.; Mohammed, O. F. Molecular Behavior of ZeroDimensional Perovskites. Sci. Adv. 2017, 3, No. e1701793.

(15) Kang, B.; Biswas, K. Exploring Polaronic, Excitonic Structures and Luminescence in $\mathrm{Cs}_{4} \mathrm{PbBr}_{6} / \mathrm{CsPbBr}_{3}$. J. Phys. Chem. Lett. 2018, 9, 830-836.

(16) Ju, M. G.; Dai, J.; Ma, L.; Zhou, Y. Y.; Zeng, X. C. ZeroDimensional Organic-Inorganic Perovskite Variant: Transition between Molecular and Solid Crystal. J. Am. Chem. Soc. 2018, 140, 10456-10463.

(17) Saidaminov, M. I.; Almutlaq, J.; Sarmah, S.; Dursun, I.; Zhumekenov, A. A.; Begum, R.; Pan, J.; Cho, N.; Mohammed, O. F.; Bakr, O. M. Pure $\mathrm{Cs}_{4} \mathrm{PbBr}_{6}$ : Highly Luminescent Zero Dimensional Perovskite Solids. ACS Energy Lett. 2016, 1, 840-845.

(18) Yin, J.; Yang, H.; Song, K.; El-Zohry, A. M.; Han, Y.; Bakr, O. M.; Bredas, J. L.; Mohammed, O. F. Point Defects and Green Emission in Zero-Dimensional Perovskites. J. Phys. Chem. Lett. 2018, 9, 5490-5495.

(19) Akkerman, Q. A.; Abdelhady, A. L.; Manna, L. ZeroDimensional Cesium Lead Halides: History, Properties, and Challenges. J. Phys. Chem. Lett. 2018, 9, 2326-2337.

(20) Wang, L.; Liu, H.; Zhang, Y.; Mohammed, O. F. The Photoluminescence Origin of Zero-Dimensional $\mathrm{Cs}_{4} \mathrm{PbBr}_{6}$ Perovskite. ACS Energy Lett. 2020, 5, 87-99.

(21) Jung, Y. K.; Calbo, J.; Park, J. S.; Whalley, L. D.; Kim, S.; Walsh, A. Intrinsic Doping Limit and Defect-Assisted Luminescence in $\mathrm{Cs}_{4} \mathrm{PbBr}_{6}$. J. Mater. Chem. A 2019, 7, 20254-20261.

(22) Seth, S.; Samanta, A. Photoluminescence of Zero-Dimensional Perovskites and Perovskite-Related Materials. J. Phys. Chem. Lett. 2018, 9, 176-183.

(23) Cortecchia, D.; Yin, J.; Petrozza, A.; Soci, C. White Light Emission in Low-Dimensional Perovskites. J. Mater. Chem. C 2019, 7, 4956-4969.

(24) Li, S. R.; Luo, J. J.; Liu, J.; Tang, J. Self-Trapped Excitons in AllInorganic Halide Perovskites: Fundamentals, Status, and Potential Applications. J. Phys. Chem. Lett. 2019, 10, 1999-2007.

(25) Ma, Z.; Liu, Z.; Lu, S.; Wang, L.; Feng, X.; Yang, D.; Wang, K.; Xiao, G.; Zhang, L.; Redfern, S. A. T.; Zou, B.; et al. Pressure-Induced Emission of Cesium Lead Halide Perovskite Nanocrystals. Nat. Commun. 2018, 9, 4506.

(26) Nikl, M.; Mihokova, E.; Nitsch, K. Photoluminescence and Decay Kinetics of $\mathrm{Cs}_{4} \mathrm{PbCl}_{6}$ Single-Crystals. Solid State Commun. 1992, 84, 1089-1092.

(27) Nikl, M.; Mihokova, E.; Nitsch, K.; Somma, F.; Giampaolo, C.; Pazzi, G. P.; Fabeni, P.; Zazubovich, S. Photoluminescence of $\mathrm{Cs}_{4} \mathrm{PbBr}_{6}$ Crystals and Thin Films. Chem. Phys. Lett. 1999, 306, 280284.

(28) Zhang, Z. J.; Zhu, Y. M.; Wang, W. L.; Zheng, W.; Lin, R. C.; Li, X. B.; Zhang, H.; Zhong, D. Y.; Huang, F. Aqueous Solution Growth of Millimeter-Sized Nongreen-Luminescent Wide Bandgap $\mathrm{Cs}_{4} \mathrm{PbBr}_{6}$ Bulk Crystal. Cryst. Growth Des. 2018, 18, 6393-6398.

(29) Myagkota, S. V.; Savchin, P. V.; Voloshinovskii, A. S.; Demkiv, T. M.; Boiko, Y. V.; Vus, R. S.; Demkiv, L. S. Luminescence Properties of the $\mathrm{CsSnBr}_{3}$ Phase in Metastable $\mathrm{Cs}_{4} \mathrm{SnBr}_{6}$. Phys. Solid State 2008, 50, 1473-1476.

(30) Alkauskas, A.; Lyons, J. L.; Steiauf, D.; Van de Walle, C. G. First-Principles Calculations of Luminescence Spectrum Line Shapes for Defects in Semiconductors: The Example of GaN and ZnO. Phys. Rev. Lett. 2012, 109, 267401.

(31) Luo, J. J.; Wang, X. M.; Li, S. R.; Liu, J.; Guo, Y. M.; Niu, G. D.; Yao, L.; Fu, Y. H.; Gao, L.; Dong, Q. S.; et al. Efficient and Stable Emission of Warm-White Light from Lead-Free Halide Double Perovskites. Nature 2018, 563, 541-545.

(32) Kresse, G.; Furthmuller, J. Efficient Iterative Schemes for Ab Initio Total-Energy Calculations Using a Plane-Wave Basis Set. Phys. Rev. B: Condens. Matter Mater. Phys. 1996, 54, 11169-11186.

(33) Kresse, G.; Joubert, D. From Ultrasoft Pseudopotentials to the Projector Augmented-Wave Method. Phys. Rev. B: Condens. Matter Mater. Phys. 1999, 59, 1758-1775.
(34) Giannozzi, P.; Baroni, S.; Bonini, N.; Calandra, M.; Car, R.; Cavazzoni, C.; Ceresoli, D.; Chiarotti, G. L.; Cococcioni, M.; Dabo, I.; et al. Quantum Espresso: A Modular and Open-Source Software Project for Quantum Simulations of Materials. J. Phys.: Condens. Matter 2009, 21, 395502.

(35) Giannozzi, P; Andreussi, O; Brumme, T; Bunau, O; Buongiorno Nardelli, M; Calandra, M; Car, R; Cavazzoni, C; Ceresoli, D; Cococcioni, M; Colonna, N; Carnimeo, I; Dal Corso, A; de Gironcoli, S; Delugas, P; DiStasio, R A; Ferretti, A; Floris, A; Fratesi, G; Fugallo, G; Gebauer, R; Gerstmann, U; Giustino, F; Gorni, T; Jia, J; Kawamura, M; Ko, H-Y; Kokalj, A; Kucukbenli, E; Lazzeri, M; Marsili, M; Marzari, N; Mauri, F; Nguyen, N L; Nguyen, H-V; Otero-de-la-Roza, A; Paulatto, L; Ponce, S; Rocca, D; Sabatini, R; Santra, B; Schlipf, M; Seitsonen, A P; Smogunov, A; Timrov, I; Thonhauser, T; Umari, P; Vast, N; Wu, X; Baroni, S Advanced Capabilities for Materials Modelling with Quantum Espresso. J. Phys.: Condens. Matter 2017, 29, 465901.

(36) Faure, S.; Stern, C.; Guilard, R.; Harvey, P. D. Role of the Spacer in the Singlet-Singlet Energy Transfer Mechanism (Forster vs Dexter) in Cofacial Bisporphyrins. J. Am. Chem. Soc. 2004, 126, 1253-1261.

(37) Lu, T.; Chen, F. W. Multiwfn: A Multifunctional Wavefunction Analyzer. J. Comput. Chem. 2012, 33, 580-592.

(38) Caricato, M.; Curutchet, C.; Mennucci, B.; Scalmani, G. Electronic Couplings for Resonance Energy Transfer from CCSD Calculations: From Isolated to Solvated Systems. J. Chem. Theory Comput. 2015, 11, 5219-5228.

(39) Azarias, C.; Russo, R.; Cupellini, L.; Mennucci, B.; Jacquemin, D. Modeling Excitation Energy Transfer in Multi-Bodipy Architectures. Phys. Chem. Chem. Phys. 2017, 19, 6443-6453.

(40) Lax, M. The Franck-Condon Principle and Its Application to Crystals. J. Chem. Phys. 1952, 20, 1752-1760.

(41) Stoneham, A. M. Theory of Defects in Solids; Oxford University Press: Oxford, 1975.

(42) Ruhoff, P. T. Recursion Relations for Multi-Dimensional Franck-Condon Overlap Integrals. Chem. Phys. 1994, 186, 355-374.

(43) Wang, X. M.; Meng, W. W.; Liao, W. Q.; Wang, J. B.; Xiong, R. G.; Yan, Y. F. Atomistic Mechanism of Broadband Emission in Metal Halide Perovskites. J. Phys. Chem. Lett. 2019, 10, 501-506.

(44) https://github.com/wxiaom86 (accessed: July 1, 2019).

(45) Cortecchia, D.; Yin, J.; Bruno, A.; Lo, S. Z. A.; Gurzadyan, G. G.; Mhaisalkar, S.; Bredas, J. L.; Soci, C. Polaron Self-Localization in White-Light Emitting Hybrid Perovskites. J. Mater. Chem. C 2017, 5, 2771-2780.

(46) Yin, J.; Li, H.; Cortecchia, D.; Soci, C.; Bredas, J. L. Excitonic and Polaronic Properties of 2D Hybrid Organic-Inorganic Perovskites. ACS Energy Lett. 2017, 2, 417-423.

(47) Li, T.; Chen, X.; Wang, X.; Lu, H.; Yan, Y.; Beard, M. C.; Mitzi, D. B. Origin of Broad-Band Emission and Impact of Structural Dimensionality in Tin-Alloyed Ruddlesden-Popper Hybrid Lead Iodide Perovskites. ACS Energy Lett. 2020, 5, 347-352.

(48) Cohen, E.; Sturge, M. D. Excited-States of Excitons Bound to Nitrogen Pairs in Gap. Phys. Rev. B 1977, 15, 1039-1051.

(49) Kim, S.; Herman, I. P.; Moore, K. L.; Hall, D. G.; Bevk, J. Hydrostatic Pressure Dependence of Isoelectronic Bound Excitons in Beryllium-Doped Silicon. Phys. Rev. B: Condens. Matter Mater. Phys. 1996, 53, 4434-4442.

(50) Kang, B.; Biswas, K. Exploring Polaronic, Excitonic Structures and Luminescence in $\mathrm{Cs}_{4} \mathrm{PbBr}_{6} / \mathrm{CsPbBr}_{3}$. J. Phys. Chem. Lett. 2018, 9, $830-836$

(51) McCall, K. M.; Stoumpos, C. C.; Kostina, S. S.; Kanatzidis, M. G.; Wessels, B. W. Strong Electron-Phonon Coupling and SelfTrapped Excitons in the Defect Halide Perovskites $\mathrm{A}_{3} \mathrm{M}_{2} \mathrm{I}_{9}(\mathrm{~A}=\mathrm{Cs}$, $\mathrm{Rb} ; \mathrm{M}=\mathrm{Bi}, \mathrm{Sb})$. Chem. Mater. 2017, 29, 4129-4145. 